\title{
Shields of Melanesia de Harry Beran and Barry Craig
}

\section{Gilles Bounoure}

\section{(2) OpenEdition}

\section{Journals}

\section{Édition électronique}

URL : http://journals.openedition.org/jso/2332

DOI : 10.4000/jso.2332

ISSN : $1760-7256$

\section{Éditeur}

Société des océanistes

\section{Édition imprimée}

Date de publication : 15 décembre 2008

Pagination : 358-359

ISBN : 978-2-85430-012-3

ISSN : 0300-953x

\section{Référence électronique}

Gilles Bounoure, "Shields of Melanesia de Harry Beran and Barry Craig », Journal de la Société des Océanistes [En ligne], 126-127 | Année 2008, mis en ligne le 01 décembre 2008, consulté le 22 septembre 2020. URL : http://journals.openedition.org/jso/2332 ; DOI : https://doi.org/10.4000/jso 2332

Ce document a été généré automatiquement le 22 septembre 2020.

(ㄷ) Tous droits réservés 


\title{
Shields of Melanesia de Harry Beran and Barry Craig
}

\author{
Gilles Bounoure
}

\section{RÉFÉRENCE}

Harry Beran and Barry Craig (eds), Shields of Melanesia, préface de Jim Specht, contributions de Todd Barlin, Chris Boylan, Eric Coote, Tony Crawford, Reg MacDonald, Bill Evans, Adrienne Kaeppler, Elizabeth Price, Noelle Rathmell-Stiels, Honolulu, Crawford House Publishing-University of Hawaii Press, xx-290 p., bibliogr., index, cartes, très nombreuses ill. couleur et noir en blanc.

1 Annoncé depuis plusieurs années, ce travail collectif à caractère encyclopédique prolonge une exposition thématique, Pacific Islands War Shields, présentée par l'Oceanic Art Society en août et septembre 2000 à la faveur des jeux Olympiques de Sydney. L'occasion était particulièrement bien choisie pour rappeler les rapports reliant de façon plus ou moins souterraine le sport, la guerre, le jeu, la fête, et certaines dimensions du sacré. Le présent volume, très attendu (y compris des nombreux amateurs de « militaria » qui se le disputent !) offre aux connaisseurs et aux chercheurs une masse considérable de documents $-80 \%$ des objets reproduits étaient inédits, assure le texte de la jaquette - où certains verront peut-être aussi des " munitions ».

Ce livre n'aurait pu être publié sans l'appui financier de collectionneurs et de galeristes, ni la contribution intellectuelle de ces "chercheurs non professionnels", en d'autres termes, voyageurs, collecteurs, courtiers et marchands d'art qui signent parfois des chapitres importants de cet ensemble organisé géographiquement. Les puristes pourraient n'y voir que travaux d'amateurs. L'un des maîtres d'œuvre du projet, Harry Beran, fut parfois tenu pour tel, en tant qu'universitaire spécialiste de philosophie, avant d'être admis sans conteste, après sa récente retraite, comme l'un des meilleurs spécialistes des arts de la région Massim. Ses vastes connaissances, qui vont bien audelà de cette aire stylistique, lui permettent ici notamment, grâce à sa maîtrise de 
l'allemand, d'offrir aux lecteurs exclusivement anglophones un précieux examen critique de l'article pionnier de Felix Speiser, «Über Schutzwaffen in Melanesien" (Internationales Archiv für Ethnographie XL, 1942).

3 Le petit livre qui avait fait connaître Barry Craig aux lecteurs européens, Art and Decoration of Central New Guinea (Shire Ethnography, Aylesbury, 1988), présentait déjà, à propos des boucliers et des panneaux de case des sociétés des Hautes-Terres, de très intéressantes précisions sur l'évolution et la diffusion probables des motifs décoratifs et des formes générales, ainsi que sur le poids et l'usage de ces objets. Le même souci du détail significatif préside au présent ouvrage: chaque fois qu'il a été possible, les dimensions des boucliers sont complétées de leur poids. Une targe de $14 \mathrm{~kg}$ (Wola, Hautes-Terres, p. 134) ne se manipule pas comme un petit écu de 450 grammes (Baie de Geelvink, p. 29). Pas plus que ce gros livre ne se manie comme l'étroit bouclier de la vallée de la Waghi pesant à peu près le même poids, $1,5 \mathrm{~kg}$ (p. 139)!

4 Les éditeurs en préviennent et Jim Specht avec eux, cette somme ne se veut ni exhaustive ni définitive. À côté des difficultés matérielles rencontrées pour son édition, l'obstacle majeur aura été la dispersion des informations, et surtout leur portée limitée ou sujette à caution. Les collecteurs et les ethnographes ont visité la plupart du temps des Mélanésiens assujettis à la "pacification » coloniale, ou déjà munis d'armes occidentales, et les inventaires de musées livrent peu d'indications de provenance réellement fiables. De l'archéologie elle-même, seule en mesure de restituer quelques traits de ces sociétés avant le contact colonial, il y a peu à attendre sur ces objets particulièrement périssables. Cela ne retire rien aux qualités de ce volume, qu'on peut tenir pour un monumental " état des connaissances », avec des avancées notables pour ce qui concerne les Hautes-Terres de Nouvelle-Guinée, bien plus familières aux contributeurs presque tous australiens qu'à leurs lecteurs des antipodes.

5 Cette réunion de données sans précédent a aussi pour mérite de mettre en relief les lacunes de l'ethnographie classique, probablement irréparables dans bien des cas, ainsi que nombre d'énigmes que cet ouvrage rappelle et propose aux recherches futures. L'une d'elles a même conduit les auteurs à accorder une place prépondérante à la Nouvelle-Guinée (cinq chapitres), au détriment de la Mélanésie insulaire (un chapitre) où, sauf en Nouvelle-Bretagne et aux îles Salomon centrales, l'usage de boucliers n'est pas attesté. Cette disparité conduisait Speiser, dans l'article précité, à faire dériver les boucliers de Nouvelle-Guinée de ces massues ou bâtons à prise centrale de la Mélanésie insulaire qui permettent à la fois de porter des coups et de détourner ceux de l'adversaire. On remarquera que l'escrime européenne a connu au contraire au $\mathrm{XVI}^{\mathrm{e}}$ siècle le remplacement du bouclier par la dague, d'abord défensive, puis de plus en plus offensive, mais il n'y a guère lieu de se référer pour la Mélanésie à cette évolution européenne, contemporaine du développement des armes à feu.

6 Entre les boucliers étroits en vannerie de Roviana, dont Carl Ribbe observait que «Sie dienen mehr zum Auffangen der Pfeile, Lanzen und Beilhiebe als zu Abwehr» (Zwei Jahre unter den Kannibalen der Salomo-Inseln, 1903, p. 302), et les massues à prise centrale des Salomon du Nord et de Nouvelle-Irlande, il faudrait également citer, certes non comme « chaînon manquant » d'une douteuse évolution, mais comme élément à ajouter au dossier, les boucliers de danse des Telei du sud de Bougainville, décrits par Richard Thurnwald et surtout par Ernst Frizzi («Ein Beitrag zur Ethnologie von Bougainville und Buka», Baessler-Archiv, Beiheft VI, 1914, p. 36, absent de la bibliographie du volume). Évoquer les boucliers de danse - sujet non moins vaste et ardu - n'est pas 
hors de propos, les auteurs de ce livre signalant souvent les intrications entre les gestuelles guerrières de la fête et la chorégraphie des combats, qu'on retrouve même dans les mœurs de l'Europe moderne.

7 Incluant dans son inventaire de l'arsenal défensif jusqu'aux «boucliers de bras » dont se protégeaient les archers de divers lieux de Nouvelle-Guinée, ce volume évoque aussi à plusieurs reprises les armures en tant que substituts ou accessoires des boucliers. Le bref exposé que consacre A. L. Kaeppler aux usages guerriers et aux armes de Polynésie et de Micronésie fait évidemment mention des armures des îles Gilbert (aujourd'hui Kiribati), spectaculaires cuirasses de "samouraïs des mers du Sud» auxquelles on a parfois prêté d'obscures origines nipponnes ou européennes. H. Beran et E. Coote rappellent que quelques musées (dont celui du quai Branly, p. 56 de ce livre) conservent des « boucliers » ou des plastrons de protection en fibres d'écorce tressée provenant de la région de Madang et de la côte nord-est de la Nouvelle-Guinée.

8 Plus à l'ouest, pour la région de Vanimo, B. Craig, citant par ailleurs l'usage local d'armures ou de plastrons (p. 38), décrit (p. 33, et fig. 3-7) un bouclier collecté par Otto Finsch (Ethnologische Erfahrungen..., 1888, pl. xxv, 1) mais sans la cuirasse tressée qui accompagnait apparemment son emploi (ibid., pl. xxIv, 7 et 7 a), à en croire un dessin illustrant un autre livre de Finsch (Samoa-Fahrten, 1888, «Krieger von Angriffshafen », p. 337, figurant deux guerriers cuirassés dont l'un tient le bouclier collecté par Finsch pour le musée de Vienne, et reproduit dans la publication précitée). Détail de mince portée, car disposerait-on même de la panoplie complète du guerrier de Vanimo, B. Craig a beau jeu de montrer que les descriptions laissées par Finsch ou Schultze-Jena ne contiennent guère de mode d'emploi. Il est plus curieux d'observer que les cuirasses de Vanimo sont de conception assez voisine de celles des îles Gilbert, sans doute en partie pour des raisons fonctionnelles aisées à établir, mais dont on ne saisit pas pourquoi elles se sont imposées ici et non là. Tel est plus généralement le mystère qu'agite ce précieux et beau livre, qui dissipe aussi l'image d'une Mélanésie uniformément vouée aux « guerres tribales» (celle des amateurs de «militaria»!) et la restitue dans son étonnante diversité.

\section{AUTEURS}

GILLES BOUNOURE 